ORIGINAL ARTICLE

\section{Internal Mammary and Medial Supraclavicular Irradiation in Breast Cancer}

\author{
P.M. Poortmans, S. Collette, C. Kirkove, E. Van Limbergen, V. Budach, \\ H. Struikmans, L. Collette, A. Fourquet, P. Maingon, M. Valli, K. De Winter, \\ S. Marnitz, I. Barillot, L. Scandolaro, E. Vonk, C. Rodenhuis, H. Marsiglia, \\ N. Weidner, G. van Tienhoven, C. Glanzmann, A. Kuten, R. Arriagada, \\ $\mathrm{H}$. Bartelink, and W. Van den Bogaert, for the EORTC Radiation Oncology \\ and Breast Cancer Groups*
}

A B STRACT

\section{BACKGROUND}

The effect of internal mammary and medial supraclavicular lymph-node irradiation (regional nodal irradiation) added to whole-breast or thoracic-wall irradiation after surgery on survival among women with early-stage breast cancer is unknown.

\section{METHODS}

We randomly assigned women who had a centrally or medially located primary tumor, irrespective of axillary involvement, or an externally located tumor with axillary involvement to undergo either whole-breast or thoracic-wall irradiation in addition to regional nodal irradiation (nodal-irradiation group) or whole-breast or thoracic-wall irradiation alone (control group). The primary end point was overall survival. Secondary end points were the rates of disease-free survival, survival free from distant disease, and death from breast cancer.

\section{RESULTS}

Between 1996 and 2004, a total of 4004 patients underwent randomization. The majority of patients $(76.1 \%)$ underwent breast-conserving surgery. After mastectomy, $73.4 \%$ of the patients in both groups underwent chest-wall irradiation. Nearly all patients with node-positive disease $(99.0 \%)$ and $66.3 \%$ of patients with node-negative disease received adjuvant systemic treatment. At a median follow-up of 10.9 years, 811 patients had died. At 10 years, overall survival was $82.3 \%$ in the nodal-irradiation group and $80.7 \%$ in the control group (hazard ratio for death with nodal irradiation, $0.87 ; 95 \%$ confidence interval $[\mathrm{CI}], 0.76$ to $1.00 ; \mathrm{P}=0.06$ ). The rate of disease-free survival was $72.1 \%$ in the nodal-irradiation group and $69.1 \%$ in the control group (hazard ratio for disease progression or death, 0.89; $95 \%$ CI, 0.80 to $1.00 ; \mathrm{P}=0.04$ ), the rate of distant disease-free survival was $78.0 \%$ versus $75.0 \%$ (hazard ratio, 0.86 ; $95 \% \mathrm{CI}, 0.76$ to $0.98 ; \mathrm{P}=0.02$ ), and breast-cancer mortality was $12.5 \%$ versus $14.4 \%$ (hazard ratio, $0.82 ; 95 \%$ CI, 0.70 to 0.97 ; $\mathrm{P}=0.02$ ). Acute side effects of regional nodal irradiation were modest.

\section{CONCLUSIONS}

In patients with early-stage breast cancer, irradiation of the regional nodes had a marginal effect on overall survival. Disease-free survival and distant disease-free survival were improved, and breast-cancer mortality was reduced. (Funded by Fonds Cancer; ClinicalTrials.gov number, NCT00002851.)
The authors' full names, academic degrees, and affiliations are listed in the Appendix. Address reprint requests to Dr. Poortmans at the Department of Radiation Oncology, Radboud University Medical Center, P.O. Box 9101, 6500 HB Nijmegen, the Netherlands, or at philip.poortmans@ radboudumc.nl.

*A complete list of investigators in the European Organization for Research and Treatment of Cancer (EORTC) Radiation Oncology and Breast Cancer Groups is provided in the Supplementary Appendix, available at NEJM.org.

N EnglJ Med 2015;373:317-27 DOI: 10.1056/NEJMoal415369 Copyright (c) 2015 Massachusetts Medical Society. 
T HE FIRST FILTER STATIONS FOR THE lymphatic drainage of the breast are the axillary and internal mammary lymph nodes. ${ }^{1}$ Surgical studies have shown that the incidence of metastatic involvement of the internal mammary nodes varies between $4 \%$ and $9 \%$ in patients with axillary node-negative breast cancer and between $16 \%$ and $65 \%$ in patients with axillary node-positive breast cancer. ${ }^{2-4}$ As a consequence, surgical dissection of the internal mammary nodes was attempted but abandoned in the 1970s, since no improvement in survival was observed. 4,5

Elective irradiation of the regional nodes remained widely used until the late 1980s, when it became less popular on the basis of an overview of older trials that showed no survival benefit, despite improvement in control of locoregional disease. ${ }^{6}$ There was even a suggestion of decreased long-term survival owing to irradiation of the heart. ${ }^{5-7}$ However, some studies predicted a beneficial effect in patients who had a high risk of regional involvement. ${ }^{8,9}$ Because of this controversy, many centers irradiated only the axilla and medial supraclavicular nodes in patients with risk factors and avoided the internal mammary nodes to protect the heart.

A renewed interest in the role of elective irradiation of the regional lymph nodes emerged after publication of results of studies that showed a favorable effect of postmastectomy radiation therapy and after improvement in techniques that led to less cardiac exposure. ${ }^{10-13}$ Because of the uncertainties regarding the role of internal mammary irradiation, the Radiation Oncology and Breast Cancer Groups of the European Organization for Research and Treatment of Cancer (EORTC) initiated a randomized, multicenter, phase 3 trial (EORTC 22922/10925) to investigate the effect of elective internal mammary and medial supraclavicular lymph-node irradiation (here termed regional nodal irradiation) on overall survival. Details about the study population, radiation techniques, quality-assurance program, and toxic effects after 3 years of follow-up have been published previously. ${ }^{14-17}$ We report here the final analysis of the primary and secondary end points, after a median follow-up of 10.9 years. Longterm analyses are planned after a median followup of 15 and 20 years.
METHODS

\section{PATIENTS}

From July 1996 through January 2004, a total of 4004 patients were enrolled at 46 institutions in 13 countries. Eligibility criteria included unilateral histologically confirmed breast adenocarcinoma of stage I, II, or III with a centrally or medially located primary tumor, irrespective of axillary involvement, or an externally located tumor with axillary involvement. Eligible patients had undergone mastectomy or breastconserving surgery and axillary dissection. During the last years of the trial, patients were eligible if they had undergone a sentinel-node biopsy followed by an axillary dissection in the case of a positive node.

\section{STUDY DESIGN AND OVERSIGHT}

After written informed consent was obtained from all patients, randomization was performed centrally at the EORTC headquarters. Patients were assigned to undergo regional nodal irradiation (at a dose of $50 \mathrm{~Gy}$ in 25 fractions) or no regional nodal irradiation. A minimization algorithm for randomization in a 1:1 ratio was used to stratify group assignments according to institution, menopausal status, tumor site within the breast, type of breast surgery, type of axillary dissection, pathological tumor stage, and pathological nodal stage.

During follow-up, patients were seen annually for the first 5 years and then every 2 years unless disease recurrence or death occurred. In addition to the patient's performance status (according to the Eastern Cooperative Oncology Group scale), the presence of any clinical evidence of lung or cardiac fibrosis, cardiac disease, and other late toxic effects (scored on the basis of the patient's history and, if symptoms were present, on further examination) was scored. Annual chest radiography was recommended. Data on serious adverse events were not collected. Data collection and analysis were performed at the EORTC headquarters.

The study was designed by the authors, who vouch for the accuracy and completeness of the data and fidelity to the study protocol, which is available with the full text of this article at NEJM.org. No commercial support was provided 
for this study, and no one who is not an author contributed to writing the manuscript.

\section{END POINTS}

The primary end point was overall survival. Secondary end points were the rates of disease-free survival, distant disease-free survival, and death from breast cancer.

Overall survival was calculated from the date of randomization to the date of death from any cause. Disease-free survival was calculated from the date of randomization to the first date of local recurrence, regional recurrence, distant recurrence, second breast cancer, or death from any cause, whichever occurred first. Distant disease-free survival was calculated from the date of randomization to the first date of distant disease or death from any cause, whichever occurred first. Death from breast cancer was calculated from the date of randomization to the date of death from breast cancer; the other causes of death were considered to be competing risks. Time to any first recurrence of breast cancer was calculated from the date of randomization to the first date of local recurrence, regional recurrence, distant disease, death from breast cancer, or a second ipsilateral breast cancer, whichever occurred first.

Contralateral breast cancer, a second cancer other than breast cancer, and death due to other causes were considered to be competing risks. For all end points, data on patients who had had no event at the cutoff date for the final analysis were censored at the date of the last follow-up.

\section{STATISTICAL ANALYSIS}

The trial was designed to detect a difference of 4 percentage points (79\% vs. $75 \%$ ) in 10 -year overall survival with whole-breast or thoracicwall irradiation in addition to regional nodal irradiation as compared with whole-breast or thoracic-wall irradiation alone (hazard ratio for death, 0.82). We estimated that 4000 patients would be needed for 791 deaths to occur, which would give the study $80 \%$ power at a two-sided significance level of $5 \%$ to detect a 4 percentagepoint difference, assessed by means of the logrank test. Time-to-event curves were estimated by the Kaplan-Meier method and compared with the use of a two-sided log-rank test. The cumu- lative incidences of death from breast cancer and the first recurrence of breast cancer were compared by means of the Fine-Gray test.

Exploratory analyses were performed to test the heterogeneity of treatment effect for overall and disease-free survival across prespecified subgroups defined according to the stratification factors, and forest plots were used to present the results. Data on all patients who underwent randomization were analyzed according to the intention-to-treat principle. Analyses were performed with the use of SAS software, version 9.4 (SAS Institute).

\section{RESULTS}

\section{PATIENT AND TUMOR CHARACTERISTICS}

Of the 4004 patients who underwent randomization, $32(0.8 \%)$ were clinically ineligible, mainly because of concurrent disease or a tumor stage that did not meet the eligibility criteria. Another 106 patients $(2.6 \%)$ were not treated according to the protocol (Fig. 1). The characteristics of the patients were similar in the two study groups (Table 1; and Table S1 in the Supplementary Appendix, available at NEJM.org). The median age was 54 years. In $95.8 \%$ of the patients, the primary tumor was $5 \mathrm{~cm}$ or smaller, and $87.5 \%$ of the patients had either no involved axillary nodes or one to three involved axillary nodes. Details regarding axillary surgery are summarized in Table S2 in the Supplementary Appendix.

\section{TREATMENT}

A total of $76.1 \%$ of the patients had breast-conserving surgery followed by whole-breast radiation therapy; in $85.1 \%$ of these patients, this radiation therapy was followed by boost irradiation to the primary tumor bed. After mastectomy, $73.4 \%$ of the patients underwent chest-wall irradiation. A total of $7.4 \%$ of the patients in the control group and $8.3 \%$ of the patients in the nodal-irradiation group underwent axillary irradiation. The radiation treatment target volume consisted of the first three intercostal spaces, up to and including the first five intercostal spaces in patients with lower inner-quadrant tumors. The supraclavicular field laterally reached the acromioclavicular joint, the apical axillary clips 


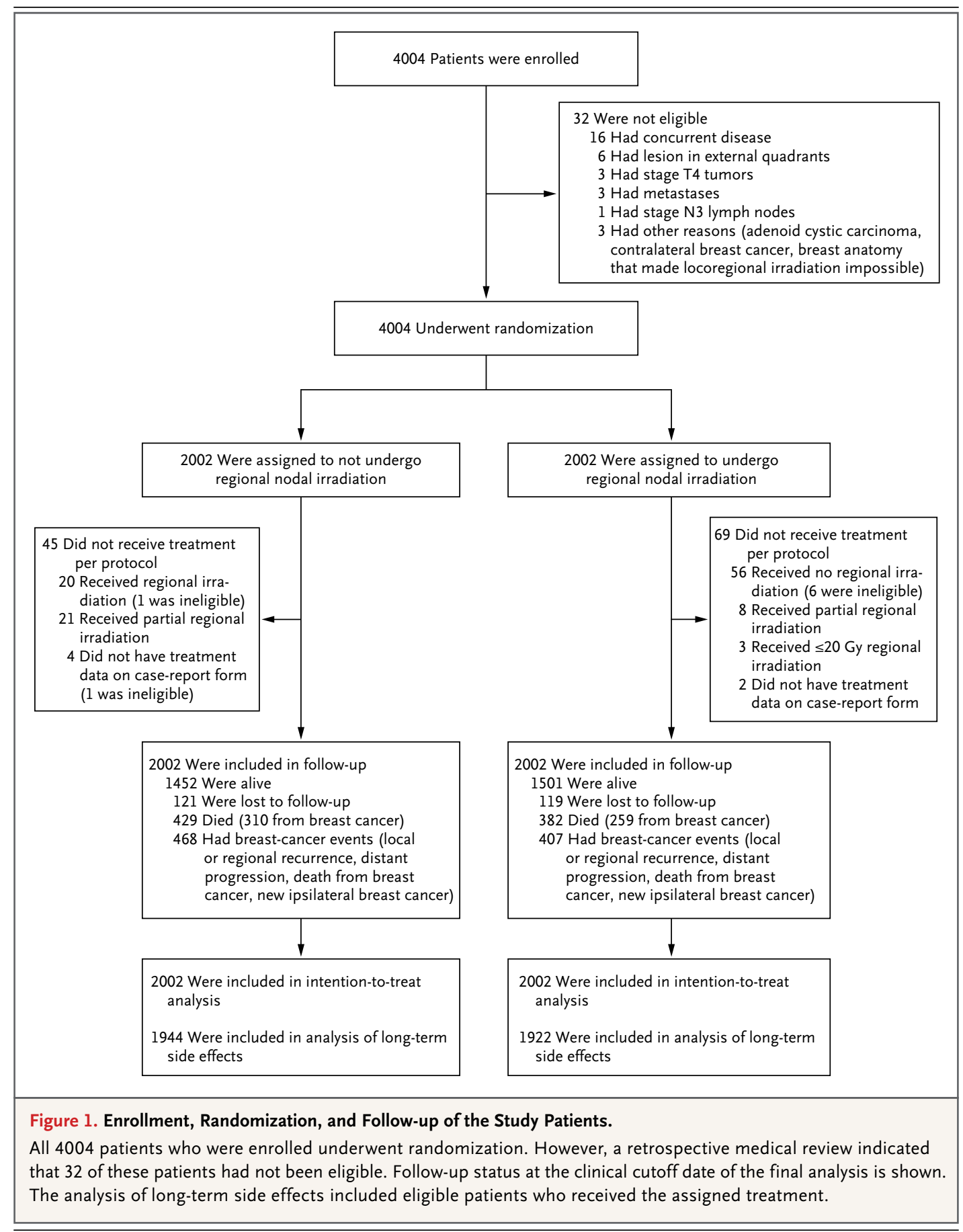

positioned by the surgeon, or both, thereby including the upper part of the axilla. ${ }^{15}$

Adjuvant systemic therapy was administered depending on risk factors, including nodal involvement, tumor size and grade, and patient age. Nearly all patients with node-positive disease $(99.0 \%)$ and $66.3 \%$ of patients with node-nega- tive disease received systemic treatment (Table S3 in the Supplementary Appendix), but the details of that treatment were not obtained. A total of 41 patients who were randomly assigned to the control group (2.0\%) and 1944 patients who were randomly assigned to the nodal-irradiation group (97.1\%) underwent regional nodal irradia- 


\begin{tabular}{|c|c|c|c|}
\hline Characteristic & $\begin{array}{l}\text { Control } \\
\text { Group } \\
(\mathrm{N}=2002)\end{array}$ & $\begin{array}{c}\text { Nodal-Irradiation } \\
\text { Group } \\
(\mathrm{N}=2002)\end{array}$ & $\begin{array}{c}\text { Total } \\
(\mathrm{N}=4004)\end{array}$ \\
\hline \multicolumn{4}{|l|}{ Age $-y r$} \\
\hline Median & 54.0 & 54.0 & 54.0 \\
\hline Range & $22.0-75.0$ & $19.0-75.0$ & $19.0-75.0$ \\
\hline \multicolumn{4}{|l|}{ Type of surgery - no. (\%) } \\
\hline Mastectomy & $479(23.9)$ & $476(23.8)$ & 955 (23.9) \\
\hline Breast-conserving surgery & $1523(76.1)$ & $1526(76.2)$ & $3049(76.1)$ \\
\hline \multicolumn{4}{|l|}{ Pathological tumor stage - no. (\%) } \\
\hline pTl: $\leq 2 \mathrm{~cm}$ & $1203(60.1)$ & $1205(60.2)$ & $2408(60.1)$ \\
\hline pT2: $2-5 \mathrm{~cm}$ & $714(35.7)$ & $716(35.8)$ & $1430(35.7)$ \\
\hline pT3: $>5 \mathrm{~cm}$ & $71(3.5)$ & $70(3.5)$ & $141(3.5)$ \\
\hline \multicolumn{4}{|l|}{ Pathological nodal stage — no. (\%) } \\
\hline pNO: no axillary lymph nodes involved & $890(44.5)$ & $888(44.4)$ & $1778(44.4)$ \\
\hline pNla: 1-3 axillary lymph nodes involved & $866(43.3)$ & 859 (42.9) & $1725(43.1)$ \\
\hline pN2a: 4-9 axillary lymph nodes involved & $201(10.0)$ & $195(9.7)$ & $396(9.9)$ \\
\hline pN3a: $>9$ axillary lymph nodes involved & $44(2.2)$ & $59(2.9)$ & $103(2.6)$ \\
\hline \multicolumn{4}{|l|}{ Adjuvant treatment - no. (\%) } \\
\hline None & $301(15.0)$ & $324(16.2)$ & $625(15.6)$ \\
\hline Chemotherapy & $500(25.0)$ & $494(24.7)$ & $994(24.8)$ \\
\hline Hormonal therapy & $599(29.9)$ & $586(29.3)$ & $1185(29.6)$ \\
\hline Both chemotherapy and hormonal therapy & $602(30.1)$ & 598 (29.9) & $1200(30.0)$ \\
\hline
\end{tabular}

* The control group received whole-breast or thoracic-wall irradiation alone, as compared with the nodal-irradiation group, which received whole-breast or thoracic-wall irradiation in addition to regional nodal irradiation. There were no significant differences between the groups.

tion (1936 patients underwent regional irradiation and 8 patients underwent partial regional irradiation).

\section{LONG-TERM SIDE EFFECTS}

In the 3866 eligible patients who received the assigned treatment, toxic effects were evaluated at all follow-up visits before disease progression or the development of a new primary cancer. This evaluation showed that after 10 years of follow-up, $3 \%$ of the patients had pulmonary fibrosis $(4.4 \%$ in the nodal-irradiation group vs. $1.7 \%$ in the control group, $\mathrm{P}<0.001), 1 \%$ had cardiac fibrosis ( $1.2 \%$ vs. $0.6 \%, \mathrm{P}=0.06)$, and $6 \%$ had cardiac disease $(6.5 \%$ vs. $5.6 \%, \mathrm{P}=0.25)$. No significant difference was observed between the two study groups with respect to other late toxic effects or performance status. As compared with the previous 3 -year morbidity report, ${ }^{17}$ we found an increase in the risk of pulmonary fibrosis (from $0.9 \%$ to $1.7 \%$ in the control group and from $2.8 \%$ to $4.4 \%$ in the nodal-irradiation group). A total of 191 second cancers were diagnosed in the nodal-irradiation group and 222 were diagnosed in the control group.

\section{DISEASE-FREE SURVIVAL AND DISTANT DISEASE-FREE SURVIVAL}

The type and frequency of events are shown in Table 2. At the time of the final analysis, recurrence of disease in the regional nodes had developed in 139 patients, local recurrences had developed in 219 patients, and distant disease had developed in 711 patients. Disease-free survival at 10 years was $72.1 \%$ ( $95 \%$ confidence interval [CI], 70.0 to 74.1 ) in the nodal-irradiation group and $69.1 \%$ (95\% CI, 66.9 to 71.2 ) in the control group (hazard ratio for disease progression or death, 0.89 ; 95\% CI, 0.80 to $1.00 ; \mathrm{P}=0.04$ ) (Fig. $\mathrm{S} 1 \mathrm{~A}$ in the Supplementary Appendix). Distant 


\begin{tabular}{|c|c|c|c|}
\hline Event & $\begin{array}{l}\text { Control } \\
\text { Group } \\
(\mathrm{N}=2002)\end{array}$ & $\begin{array}{l}\text { Nodal-Irradiation } \\
\text { Group } \\
(\mathbf{N}=2002) \\
\text { no. of patients (\%) }\end{array}$ & $\begin{array}{c}\text { Total } \\
(\mathrm{N}=4004)\end{array}$ \\
\hline \multicolumn{4}{|l|}{ Recurrence } \\
\hline Local & $107(5.3)$ & $112(5.6)$ & $219(5.5)$ \\
\hline Regional* & $85(4.2)$ & $54(2.7)$ & $139(3.5)$ \\
\hline Axillary & $38(1.9)$ & $27(1.3)$ & $65(1.6)$ \\
\hline Medial supraclavicular & $41(2.0)$ & $30(1.5)$ & $71(1.8)$ \\
\hline Internal mammary & $16(0.8)$ & $4(0.2)$ & $20(0.5)$ \\
\hline Distant disease & $392(19.6)$ & $319(15.9)$ & $711(17.8)$ \\
\hline \multicolumn{4}{|l|}{ Second cancer } \\
\hline Any & $222(11.1)$ & $191(9.5)$ & $413(10.3)$ \\
\hline Ipsilateral or contralateral breast cancer & $105(5.2)$ & $97(4.8)$ & $202(5.0)$ \\
\hline
\end{tabular}

* Multiple locations of regional recurrence may have been observed.

disease-free survival at 10 years was $78.0 \%$ (95\% CI, 76.1 to 79.8) among patients who underwent regional nodal irradiation and $75.0 \%(95 \% \mathrm{CI}$, 73.0 to 77.0) among patients who did not undergo regional nodal irradiation $(\mathrm{P}=0.02)$ (Fig. 2A). The rate of any first recurrence of breast cancer at 10 years was $19.4 \%$ (95\% CI, 17.6 to 21.1 ) in the nodal-irradiation group, as compared with $22.9 \%$ (95\% CI, 21.0 to 24.8 ) in the control group $(\mathrm{P}=0.02)$ (Fig. $\mathrm{S} 2$ in the Supplementary Appendix). The number needed to treat to avoid one relapse of breast cancer was 30 .

\section{OVERALL SURVIVAL AND BREAST-CANCER MORTALITY}

In total, 382 patients who underwent regional nodal irradiation and 429 patients who did not undergo regional nodal irradiation died. In both groups, the main cause of death was breast cancer (259 patients in the nodal-irradiation group and 310 patients in the control group). Overall survival at 10 years was $82.3 \%$ (95\% CI, 80.4 to 83.9) among patients who underwent regional nodal irradiation and $80.7 \%$ (95\% CI, 78.8 to 82.5 ) among patients who did not undergo regional nodal irradiation $(\mathrm{P}=0.06)$ (Fig. 2B). The benefit with respect to overall survival remained borderline significant with simultaneous adjustment for the stratification factors $(\mathrm{P}=0.05)$.

At 10 years, the rate of death from breast cancer was $12.5 \%$ (95\% CI, 11.0 to 14.0 ) among patients in the nodal-irradiation group and 14.4\% (95\% CI, 12.8 to 16.0) among patients in the control group ( $\mathrm{P}=0.02)$ (hazard ratio, $0.82 ; 95 \%$ $\mathrm{CI}, 0.70$ to $0.97 ; \mathrm{P}=0.02)$. The number needed to treat to avoid one death from breast cancer was 39 for the entire patient population. Data are provided in Figure S1B in the Supplementary Appendix.

\section{RISK GROUPS}

The treatment effect on all end points was independent of all stratification factors $(\mathrm{P}>0.10)$ (Fig. 3, and Fig. S3 in the Supplementary Appendix). We found a slightly more pronounced benefit of regional nodal irradiation with respect to overall survival when both chemotherapy and hormonal therapy were administered as adjuvant systemic therapy (hazard ratio for death, 0.72; $95 \%$ CI, 0.55 to 0.94$)$. However, this effect may reflect some difference in the biology of hormone receptor-positive tumors, since adjuvant therapies were not randomly assigned (Fig. S4 in the Supplementary Appendix).

\section{DISCUSSION}

At a median follow-up of 10.9 years, our study showed that irradiation of the internal mammary and medial supraclavicular lymph nodes (regional nodal irradiation) was associated with a small but significant benefit with respect to 


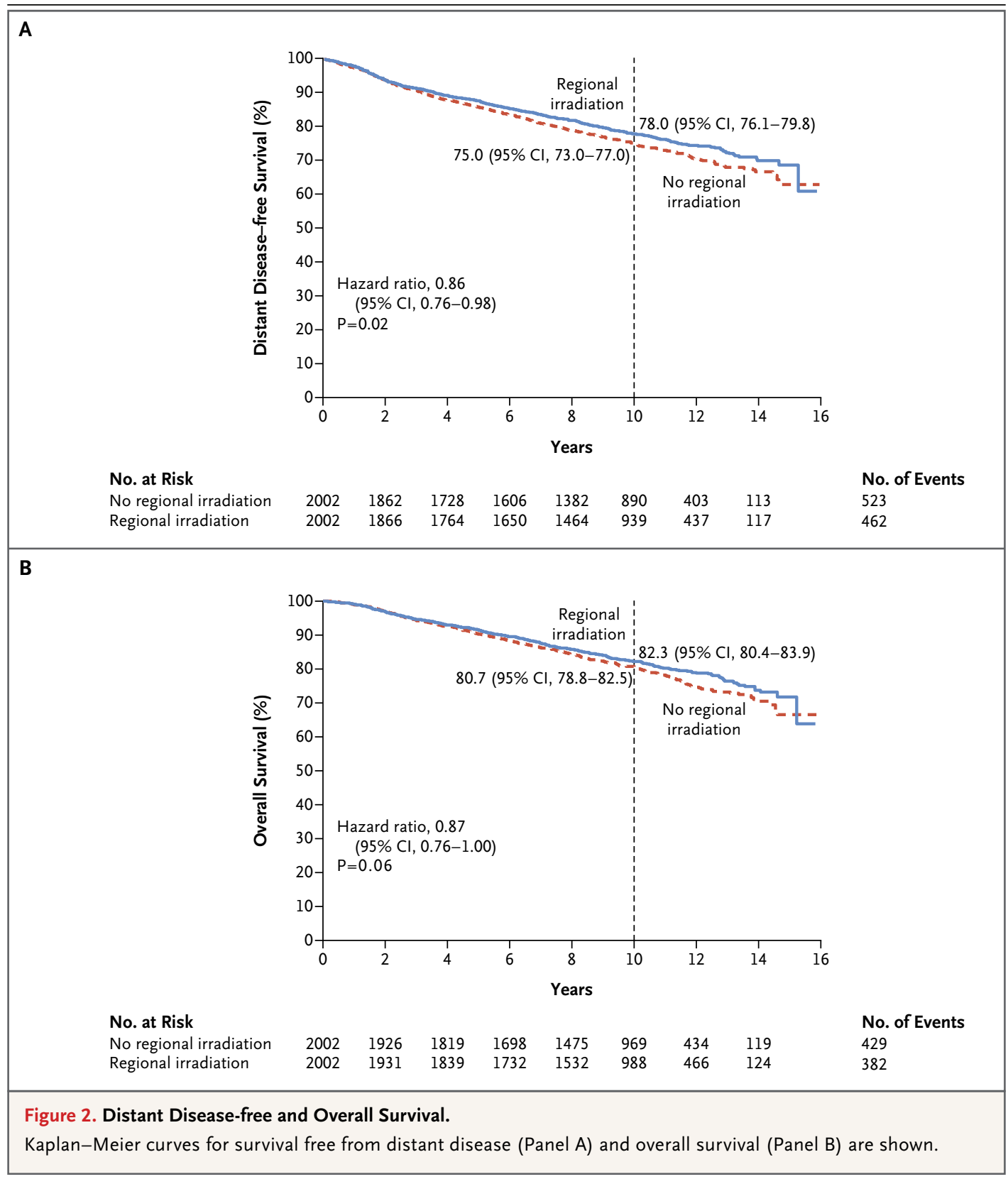

the rates of disease-free survival, distant diseasefree survival, and death from breast cancer. Overall survival at 10 years exceeded $80 \%$, and the main cause of death remained breast cancer (67.8\% in the nodal-irradiation group vs. $72.3 \%$ in the control group). We did not observe significant differences between the randomization groups with respect to other causes of death. Although there was a trend toward improvement in the rate of overall survival in the entire patient cohort, this could not be confirmed by means of the unadjusted log-rank test (hazard ratio for death, $0.87 ; 95 \% \mathrm{CI}, 0.76$ to $1.00 ; \mathrm{P}=0.06$ ).

The recently published meta-analysis of the Early Breast Cancer Trialists' Collaborative Group included individual data on 8135 women from 22 trials who were treated with mastectomy and axillary surgery and were randomly assigned to undergo or not undergo locoregional irradiation. ${ }^{18}$ In patients who had involved axillary nodes after axillary dissection, locoregional irradiation was associated with significantly lower 


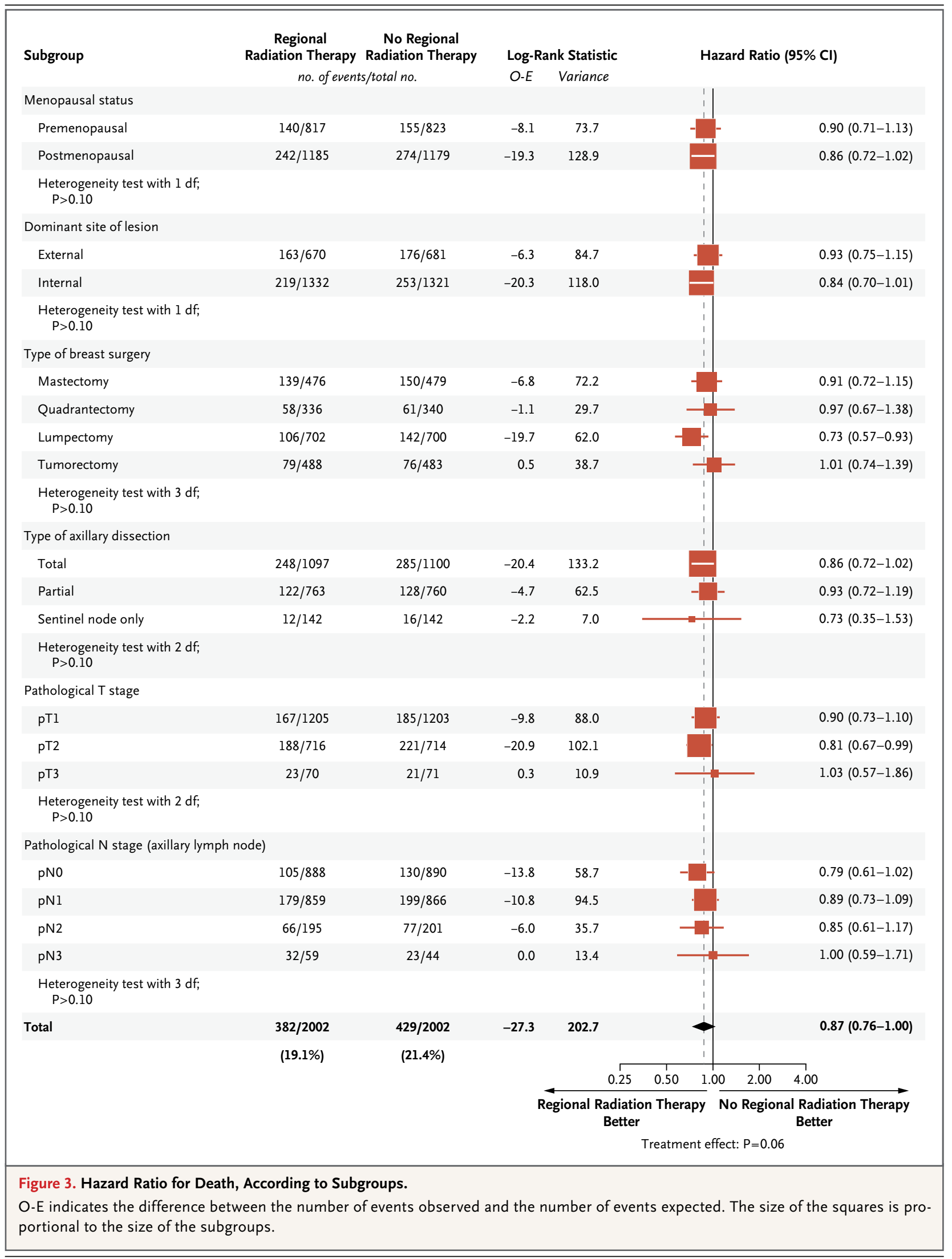

The New England Journal of Medicine

Downloaded from nejm.org at RADBOUD UNIVERSITEIT NIJMEGEN on March 6, 2017. For personal use only. No other uses without permission. 
rates of regional and overall recurrences and death from breast cancer. This benefit was independent of the number of involved axillary nodes (the decrease in the rate of any recurrence was $11.5 \%$ among women with one to three involved axillary nodes vs. $8.8 \%$ among women with four positive nodes, and the corresponding decrease in the rate of death from breast cancer was $7.9 \%$ vs. $9.3 \%$ ). In patients with one to three involved nodes, the absolute benefit was the same with or without systemic therapy. A previous Early Breast Cancer Trialists' Collaborative Group meta-analysis, which included individual patient data on 10,801 women in 17 randomized trials, showed a similar benefit associated with postoperative irradiation after breast-conserving surgery. ${ }^{19}$

Despite this evidence in favor of postoperative irradiation in the multimodal treatment of most patients after breast-conserving therapy and for all patients with node-positive breast cancer after mastectomy, neither the individual randomized trials nor the meta-analyses provided valuable information on the effect of irradiation of the respective nodal target volumes. ${ }^{18,19}$ The role of radiation directed to the internal mammary nodes was questioned, particularly since its use was associated with radiation-associated cardiac death, which was probably attributable to outdated radiation techniques. ${ }^{20-29}$ It remains undefined whether this risk is significantly lowered by advances in radiation techniques.

The interpretation of our results is complex in the light of current developments, including a greater proportion of screen-detected cancers, the increasing use of adjuvant systemic therapy, and improving radiation-therapy techniques. ${ }^{30,31}$ The interaction among prognostic factors, the use of systemic therapy, and the benefit of improving regional control has been described previously. ${ }^{32}$ The benefit of regional-node irradiation was also seen in patients with medially or centrally located primary tumors without axillary nodal involvement.

Our results are similar to those of the $\mathrm{Na}$ tional Cancer Institute of Canada Clinical Trials Group MA.20 trial..$^{33}$ That study, which involved 1832 patients with node-positive or high-risk node-negative disease after breast-conserving therapy, showed that regional nodal irradiation was associated with improved disease-free survival and distant disease-free survival. The results of the study by Hennequin et al. showed a lack of benefit of regional nodal irradiation; however, that study was smaller than our study and the patients had a poorer outcome (a 10\% lower rate of overall survival at the 5-year follow-up and a $20 \%$ lower rate of overall survival at the 10 -year follow-up). ${ }^{34}$

We found a low rate of heart disease and death from heart disease after 10.9 years of follow-up, as has been reported before. ${ }^{17,34}$ However, Darby et al. found a dose-dependent increased risk of late ischemic heart disease associated with radiotherapy for cancer of the left breast. ${ }^{28}$ Cardiac disease after radiation therapy might have onset early after treatment. ${ }^{28}$ The radiationtherapy techniques used in our trial, guided by a thorough quality-assurance program, minimized the radiation dose to the heart, possibly to a clinically less relevant level. ${ }^{15}$ Nevertheless, additional follow-up is required to assess late cardiac complications.

As compared with the previous 3-year morbidity report, ${ }^{17}$ we found only a slight increase in the risk of pulmonary fibrosis. These results are consistent with the results of studies of late pulmonary disease after radiation therapy for breast cancer. $^{35-37}$ The low frequency of lymphedema (10.5\% in the control group and $12.0 \%$ in the nodal-irradiation group) is probably due to the fact that the operated part of the axilla was not irradiated unless adverse risk factors were present. Overall, only $7.4 \%$ of patients in the control group and $8.3 \%$ in the nodal-irradiation group underwent irradiation to the axilla.

We recognize the limitations of our study, which was initiated in the early 1990s to investigate whether elective regional nodal irradiation would improve long-term overall survival. ${ }^{38}$ Since the regional nodes are functionally interconnected, it was decided to include the medial supraclavicular nodes, thereby in fact randomizing between complete nodal treatment (axillary surgery and irradiation of nondissected nodes) and axillary surgery alone. Therefore, we cannot determine whether internal mammary irradiation or medial supraclavicular irradiation contributed more to the outcome. However, the recent results from the Danish population-based study in which patients with left-sided node-positive breast cancer underwent only medial supraclavicular irradiation, whereas patients with right-sided node-positive breast cancer underwent both internal mammary and medial supraclavicular irradiation, support the role of including the 
internal mammary chain in the success of regional nodal radiation therapy. ${ }^{39,40}$

When our trial was designed, adjuvant systemic therapy was not as variable as it is today and molecular subtypes were not yet described; thus, we recorded little information about these variables (Table S3 in the Supplementary Appendix). In the current study, the number needed to treat to avoid one death from breast cancer was 39 , and the number needed to treat to avoid one relapse of breast cancer was 30 .

In summary, we found that regional nodal irradiation was beneficial to women with earlystage breast cancer. It improved the rates of disease-free and distant disease-free survival and reduced the rate of death from breast cancer among patients with involved axillary nodes, a medially or centrally located primary tumor, or both. Improvement in the rate of overall survival was not confirmed with 10 years of follow-up. Acute side effects were modest, and the rate of death from causes other than breast cancer was not increased. Our data do not apply to patients with lateral node-negative cancers, which is the largest patient subgroup in industrialized countries. Post-treatment follow-up for a median of 20 years is ongoing.

Supported by Fonds Cancer.

Disclosure forms provided by the authors are available with the full text of this article at NEJM.org.

\section{APPENDIX}

The authors' full names and academic degrees are as follows: Philip M. Poortmans, Ph.D., Sandra Collette, M.Sc., Carine Kirkove, Ph.D., Erik Van Limbergen, Ph.D., Volker Budach, Ph.D., Henk Struikmans, Ph.D., Laurence Collette, Ph.D., Alain Fourquet, Ph.D., Philippe Maingon, M.D., Mariacarla Valli, M.D., Karin De Winter, M.D., Simone Marnitz, M.D., Isabelle Barillot, Ph.D., Luciano Scandolaro, M.D., Ernest Vonk, M.D., Carla Rodenhuis, Ph.D., Hugo Marsiglia, Ph.D., Nicola Weidner, Ph.D., Geertjan van Tienhoven, Ph.D., Christoph Glanzmann, Ph.D., Abraham Kuten, M.D., Rodrigo Arriagada, M.D., Harry Bartelink, Ph.D., and Walter Van den Bogaert, Ph.D., for the EORTC Radiation Oncology and Breast Cancer Groups

The authors' affiliations are as follows: the Department of Radiation Oncology, Radboud University Medical Center, Nijmegen (P.M.P.), Department of Radiation Oncology, Institute Verbeeten, Tilburg (P.M.P., K.D.W.), Department of Radiation Oncology, Medisch Centrum Haaglanden, The Hague (H.S.), Department of Radiation Oncology, University Medical Center Utrecht, Utrecht (H.S., C.R.), Department of Radiation Oncology, Institute for Radiation Oncology Radiotherapeutisch Instituut Stedendriehoek en Omstreken, Deventer (E.V.), Department of Radiation Oncology, Academic Medical Center (G.T.), and Department of Radiation Oncology, the Netherlands Cancer Institute-Antoni van Leeuwenhoek Hospital (H.B.), Amsterdam - all in the Netherlands; European Organization for Research and Treatment of Cancer (EORTC) Headquarters (S.C., L.C.) and Department of Radiation Oncology, University Hospital Saint-Luc, Université Catholique de Louvain (C.K.), Brussels, and Department of Radiation Oncology, University Hospital Gasthuisberg, Leuven (E.V.L., W.V.B.) - all in Belgium; Department of Radiation Oncology, Charité University Medicine Berlin, Berlin (V.B., S.M.), and Department of Radiation Oncology, University Hospital, Tübingen (N.W.) - both in Germany; Department of Radiation Oncology, Institut Curie, Paris (A.F.), Department of Radiation Oncology, Centre Georges-François Leclerc, Dijon (P.M., I.B.), Department of Radiation Oncology, Université François Rabelais, Tours (I.B.), and Department of Radiation Oncology, Gustave Roussy Cancer Center, Villejuif (H.M.) — all in France; Department of Radiation Oncology, Ospedale Regionale di Bellinzona e Valli, Bellinzona (M.V.), and Department of Radiation Oncology, University Hospital Zurich (C.G.) — both in Switzerland; Department of Radiation Oncology, Sant'Anna Hospital, Como, Italy (M.V., L.S.); Department of Radiation Oncology, Rambam Medical Center, Haifa, Israel (A.K.); and Grupo Oncológico Cooperativo Chileno de Investigación, Santiago, Chile (R.A.).

REFERENCES

1. Heuts EM, van der Ent FW, von Meyenfeldt MF, Voogd AC. Internal mammary lymph drainage and sentinel node biopsy in breast cancer - a study on 1008 patients. Eur J Surg Oncol 2009;35:252-7.

2. Estourgie SH, Nieweg OE, Olmos RA, Rutgers EJ, Kroon BB. Lymphatic drainage patterns from the breast. Ann Surg 2004;239:232-7.

3. Huang $\mathrm{O}$, Wang $\mathrm{L}$, Shen $\mathrm{K}$, et al. Breast cancer subpopulation with high risk of internal mammary lymph nodes metastasis: analysis of 2,269 Chinese breast cancer patients treated with extended radical mastectomy. Breast Cancer Res Treat 2008;107:379-87.

4. Veronesi U, Marubini E, Mariani L, Valagussa P, Zucali R. The dissection of internal mammary nodes does not improve the survival of breast cancer patients: 30-year results of a randomised trial. Eur J Cancer 1999;35:1320-5.
5. Chen RC, Lin NU, Golshan M, Harris JR, Bellon JR. Internal mammary nodes in breast cancer: diagnosis and implications for patient management - a systematic review. J Clin Oncol 2008;26:4981-9.

6. Veronesi U, Arnone P, Veronesi P, et al. The value of radiotherapy on metastatic internal mammary nodes in breast cancer: results on a large series. Ann Oncol 2008;19:1553-60.

7. Cuzick J, Stewart HJ, Peto R, et al Overview of randomized trials of postoperative adjuvant radiotherapy in breast cancer. Recent Results Cancer Res 1988 ; 111:108-29.

8. Arriagada R, Lê MG, Mouriesse H, et al. Long-term effect of internal mammary chain treatment: results of a multivariate analysis of 1195 patients with operable breast cancer and positive axillary nodes. Radiother Oncol 1988;11:213-22.

9. Arriagada R, Rutqvist LE, Mattsson A,
Kramar A, Rotstein S. Adequate locoregional treatment for early breast cancer may prevent secondary dissemination. J Clin Oncol 1995;13:2869-78.

10. Early Breast Cancer Trialists' Collaborative Group. Effects of radiotherapy and surgery in early breast cancer: an overview of the randomized trials. $\mathrm{N}$ Engl J Med 1995;333:1444-55.

11. Overgaard M, Hansen PS, Overgaard J, et al. Postoperative radiotherapy in highrisk premenopausal women with breast cancer who receive adjuvant chemotherapy. N Engl J Med 1997;337:949-55. 12. Overgaard M, Jensen MB, Overgaard J, et al. Postoperative radiotherapy in highrisk postmenopausal breast-cancer patients given adjuvant tamoxifen: Danish Breast Cancer Cooperative Group DBCG 82c randomised trial. Lancet 1999;353: 1641-8.

13. Ragaz J, Jackson SM, Le N, et al. Adju- 
vant radiotherapy and chemotherapy in node-positive premenopausal women with breast cancer. N Engl J Med 1997;337:95662.

14. Musat E, Poortmans $P$, Van den Bogaert $\mathrm{W}$, et al. Quality assurance in breast cancer: EORTC experiences in the phase III trial on irradiation of the internal mammary nodes. Eur J Cancer 2007;43:718-24.

15. Lievens Y, Poortmans P, Van den Bogaert W. A glance on quality assurance in EORTC study 22922 evaluating techniques for internal mammary and medial supraclavicular lymph node chain irradiation in breast cancer. Radiother Oncol 2001;60:257-65.

16. Poortmans P, Kouloulias V, van Tienhoven G, et al. Quality assurance in the EORTC randomized trial 22922/10925 investigating the role of irradiation of the internal mammary and medial supraclavicular lymph node chain works. Strahlenther Onkol 2006;182:576-82.

17. Matzinger $\mathrm{O}$, Heimsoth I, Poortman $\mathrm{P}$, et al. Toxicity at three years with and without irradiation of the internal mammary and medial supraclavicular lymph node chain in stage I to III breast cancer (EORTC trial 22922/10925). Acta Oncol 2010;49:24-34.

18. McGale P, Taylor C, Correa C, et al. Effect of radiotherapy after mastectomy and axillary surgery on 10-year recurrence and 20-year breast cancer mortality: meta-analysis of individual patient data for 8135 women in 22 randomised trials. Lancet 2014;383:2127-35.

19. Early Breast Cancer Trialists' Collaborative Group (EBCTCG). Effect of radiotherapy after breast-conserving surgery on 10-year recurrence and 15-year breast cancer death: meta-analysis of individual patient data for 10,801 women in $17 \mathrm{ran}$ domised trials. Lancet 2011;378:1707-16. 20. Prosnitz RG, Hubbs JL, Evans ES, et al. Prospective assessment of radiotherapyassociated cardiac toxicity in breast cancer patients: analysis of data 3 to 6 years after treatment. Cancer 2007;110:1840-50. 21. Roychoudhuri R, Robinson D, Putcha
V, Cuzick J, Darby S, Mфller H. Increased cardiovascular mortality more than fifteen years after radiotherapy for breast cancer: a population-based study. BMC Cancer 2007;7:9.

22. Bird BR, Swain SM. Cardiac toxicity in breast cancer survivors: review of potential cardiac problems. Clin Cancer Res 2008; $14: 14-24$

23. Senkus-Konefka E, Jassem J. Cardiovascular effects of breast cancer radiotherapy. Cancer Treat Rev 2007;33:578-93. 24. Doyle JJ, Neugut AI, Jacobson JS, et al. Radiation therapy, cardiac risk factors, and cardiac toxicity in early-stage breast cancer patients. Int J Radiat Oncol Biol Phys 2007;68:82-93.

25. Correa CR, Litt HI, Hwang WT, Ferrari VA, Solin LJ, Harris EE. Coronary artery findings after left-sided compared with right-sided radiation treatment for early-stage breast cancer. J Clin Oncol 2007;25:3031-7.

26. Hooning MJ, Botma A, Aleman BM, et al. Long-term risk of cardiovascular disease in 10-year survivors of breast cancer. J Natl Cancer Inst 2007;99:365-75.

27. Harris EE, Correa C, Hwang WT, et al. Late cardiac mortality and morbidity in early-stage breast cancer patients after breast-conservation treatment. J Clin Oncol 2006;24:4100-6.

28. Darby SC, Ewertz M, McGale P, et al. Risk of ischemic heart disease in women after radiotherapy for breast cancer. $\mathrm{N}$ Engl J Med 2013;368:987-98.

29. Taylor CW, McGale P, Povall JM, et al. Estimating cardiac exposure from breast cancer radiotherapy in clinical practice. Int J Radiat Oncol Biol Phys 2009;73:1061-8. 30. Osman SO, Hol S, Poortmans PM, Essers M. Volumetric modulated arc therapy and breath-hold in image-guided locoregional left-sided breast irradiation. Radiother Oncol 2014;112:17-22.

31. Offersen BV, Boersma LJ, Kirkove C, et al. ESTRO consensus guideline on target volume delineation for elective radiation therapy of early stage breast cancer. Radiother Oncol 2015;114:3-10.
32. Poortmans P. Postmastectomy radiation in breast cancer with one to three involved lymph nodes: ending the debate. Lancet 2014;383:2104-6.

33. Whelan TJ, Olivotto IA, Parulekar WR, et al. Regional nodal irradiation in earlystage breast cancer. N Engl J Med 2015; 373:307-16.

34. Hennequin C, Bossard N, ServagiVernat $S$, et al. Ten-year survival results of a randomized trial of irradiation of internal mammary nodes after mastectomy. Int J Radiat Oncol Biol Phys 2013;86:860-6.

35. Krengli M, Sacco M, Loi G, et al. Pulmonary changes after radiotherapy for conservative treatment of breast cancer: a prospective study. Int $\mathrm{J}$ Radiat Oncol Biol Phys 2008;70:1460-7.

36. Lind P. Clinical relevance of pulmonary toxicity in adjuvant breast cancer irradiation. Acta Oncol 2006;45:13-5.

37. Muren LP, Maurstad G, Hafslund R, Anker G, Dahl O. Cardiac and pulmonary doses and complication probabilities in standard and conformal tangential irradiation in conservative management of breast cancer. Radiother Oncol 2002;62. 173-83.

38. Poortmans PM, Venselaar JL, Struikmans $\mathrm{H}$, et al. The potential impact of treatment variations on the results of radiotherapy of the internal mammary lymph node chain: a quality-assurance report on the dummy run of EORTC Phase III randomized trial 22922/10925 in Stage I-III breast cancer. Int J Radiat Oncol Biol Phys 2001;49:1399-408.

39. Thorsen LBJ, Berg M, Brodersen HJ, et al. Improved survival with internal mammary node irradiation: a prospective study on 3,072 breast cancer patients. Presented at the 33rd Congress of the European Society for Therapeutic Radiology and Oncology, Vienna, April 4-8, 2014. abstract. 40. Thorsen LB, Thomsen MS, Berg M, et al. CT-planned internal mammary node radiotherapy in the DBCG-IMN study: benefit versus potentially harmful effects. Acta Oncol 2014;53:1027-34.

Copyright @ 2015 Massachusetts Medical Society

POSTING PRESENTATIONS FROM MEDICAL MEETINGS ONLINE Online posting of an audio or video recording of an oral presentation at a medical meeting, with selected slides from the presentation, is not considered prior publication. Authors should feel free to call or send e-mail to the Journal's Editorial Offices if there are any questions about this policy. 